\title{
ANÁLISES DE EMISSÕES DE GASES DO EFEITO ESTUFA EM UM SISTEMA LOGÍSTICO COM O SOFTWARE URURAU ${ }^{1}$
}

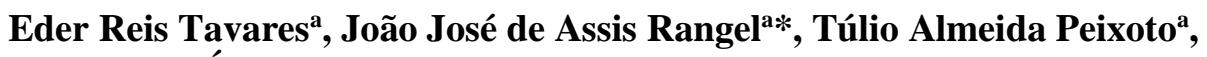 \\ Ítalo de Oliveira Matias ${ }^{\mathrm{a}}$, Fábio Freitas da Silva ${ }^{\mathrm{a}}$

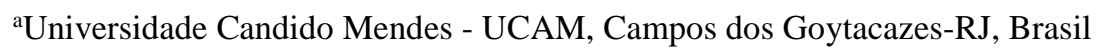

Recebido 29/02/2016, aceito 11/02/2017

\begin{abstract}
RESUMO
O presente trabalho tem como objetivo analisar um sistema logístico com emissões de gases do efeito estufa provenientes dos veículos utilizados no transporte de carga. Além disso, o estudo ainda busca demonstrar a possibilidade de utilização do software Ururau como uma ferramenta viável para avaliar este tipo de problema. Diferentes cenários foram modelados a fim de testar as funcionalidades do software, como: cálculo de emissões de gases dos veículos, otimização de variáveis do modelo e, principalmente, decisão inteligente com redes neurais artificiais. Após a etapa de testes preliminares, foram feitas as simulações dos cenários dos sistemas, aumentado gradativamente a complexidade das decisões para observar o comportamento dos modelos. Os resultados mostraram que o software pode ser viável para ser empregado para a análise do problema. Além disso, pôde-se avaliar as relações entre as variáveis relacionadas às emissões gasosas e aos custos de transporte para diferentes empresas.
\end{abstract}

Palavras-chave: Simulação a eventos discretos, Cadeia de suprimentos, Estudos ambientais, Transporte, Ururau.

\begin{abstract}
This work aims to analyze a logistics system with greenhouse gas emissions from vehicles used in the transportation of loads. Besides, the study intends to demonstrate the possibility of using the Ururau software as a viable tool to evaluate this kind of problem. Different scenarios were modeled in order to test the functionality of this software, for example, calculation of gas emissions from vehicles, optimization of model variables and, mainly, intelligent decision with artificial neural network. After the preliminary tests, the simulations of the scenarios of the systems were executed, gradually increasing the complexity of the decisions to observe the behavior of the models. Results showed that the software may be viable to be applied in the problem analysis. Moreover, it could be evaluated the relations between the variables related to the gas emissions and to the transport costs for different companies.
\end{abstract}

Keywords: Discrete event simulation, Supply chain, Environmental studies, Transport, Ururau.

*Autor para correspondência. E-mail: joao.rangel@ucam-campos.br. 


\section{Introdução}

As alterações de alguns eventos climáticos ocorridos nas últimas décadas têm alertado as autoridades mundiais sobre determinados comportamentos dos seres humanos como o elemento antropogênico responsável por este efeito. Um dos principais agentes reconhecidamente responsável por essas mudanças são as emissões de gases do efeito estufa na atmosfera (Mattila e Antikainen, 2011). Dados da Agência Internacional de Energia (IEA - Internacional Energy Agency) apontam que o setor de transportes é um dos maiores responsáveis por essas emissões. Esse setor contribui com 23\% das emissões de $\mathrm{CO}_{2}$ no mundo. Isso se dá especialmente pelo aumento, em nível mundial, do tráfego em malhas rodoviárias (IEA Statistics, 2014).

Segundo Byrne et al. (2010), por exemplo, na Zona Econômica Europeia (EEA European Economic Area) a crescente movimentação de bens por longas distâncias acarretou um aumento de $28 \%$ nas emissões de gases do efeito estufa dos 32 países pertencentes a este conjunto. Por outro lado, uma conscientização ambiental tornou as pessoas mais críticas para a concepção e operação de sistemas de Cadeia de Suprimentos (SC - supply chain, da sigla em Inglês) globalmente integradas (Sundarakani et al., 2010). Segundo Bruzzone et al. (2011) o gerenciamento da SC, que engloba o transporte de cargas entre as empresas, é um ponto chave para as organizações alcançarem seus objetivos e sua importância tem se intensificado com o processo de globalização.

Assim, o transporte de cargas em sistemas logísticos representa parte significativa tanto dos custos quanto das emissões de gases provenientes dos veículos. Diante desta questão, as empresas têm buscado cada vez mais avaliar as decisões tomadas em relação aos sistemas de logística e SC de forma mais detalhada e com foco também nas emissões gasosas geradas pelo transporte da carga. A tomada de decisão dentro de uma empresa geralmente é realizada por meio de ferramentas de apoio à decisão (Buil et al., 2011). Dentre estas ferramentas a Simulação a Eventos Discretos (SED) tem sido uma ferramenta amplamente utilizada para a análise de problemas logísticos e de SC.

Ou seja, pode-se dizer que a SED aparece, cada vez mais, como uma ferramenta para análise de questões relacionadas à sustentabilidade ambiental em sistemas logísticos e SC. Para demonstrar esta afirmação, podem ser descritos alguns trabalhos recentes sobre esse tema. Por exemplo, o estudo realizado por Silva et al. (2009) foca na simulação e na análise tecnológica para mitigar os impactos do transporte nas questões energéticas e ambientais. Adhitya et al. (2011) propõem um framework para a gestão de Green Supply Chain (GSC). Os autores integraram simulação dinâmica da SC e indicadores de ciclo de vida para avaliar impactos econômicos e ambientais de várias decisões no SC, tais como inventários, configuração de rede de distribuição e ordering policy. Em outro trabalho, Longo (2012) apresenta a necessidade de considerar diferentes aspectos de sustentabilidade no redesenho e otimização de problemas de cadeia de suprimentos. Com foco mais industrial, o trabalho de Rabe et al. (2012) discute como a simulação pode auxiliar a estabelecer um GSC flexível com foco na redução de $\mathrm{CO}_{2}$ e consumo de energia. E, também, Rangel e Cordeiro (2015) utilizaram SED para demonstrar o mecanismo de análises de emissões de veículos em um sistema logístico.

Dentro do contexto apresentado, este trabalho tem como objetivo principal analisar um sistema logístico com emissões de gases do efeito estufa provenientes dos veículos utilizados no transporte de carga. Como nos trabalhos citados, a pesquisa aborda a utilização de simulação computacional para analisar aspectos de sustentabilidade ambiental em sistemas de transporte. Além disso, este trabalho também demonstra a possibilidade de utilização do software de SED Ururau como uma ferramenta viável para estudar este tipo de problema. Esta é uma ferramenta de simulação direcionada, principalmente, a estudantes e empresas de pequeno porte.

A organização deste texto segue da seguinte forma. A segunda seção (2) descreve o simulador Ururau e os principais módulos presentes na versão 1.0 do software. A terceira seção (3) é referente à descrição do sistema proposto; nela, é apresentado o sistema logístico do problema objeto de estudo. Na quarta seção (4), foram modelados e descritos diferentes cenários do sistema proposto. A quinta seção (5) aborda os testes e análises dos resultados das simulações. Por fim, a última seção (6) traz as conclusões obtidas com este trabalho. 


\section{Software Ururau}

O Ururau é um software livre e de código fonte aberto (FOSS - Free and Open-Source Software) de SED, que utiliza como base a biblioteca de simulação JSL (Java Simulation Library) proposta por Rossetti (2008). Segundo Peixoto et al. (2014) este software permite a construção de modelos de simulação em interface gráfica (GUI - Graphic User Interface) ou mesmo a interligação de módulos na camada intermediária (JSL). Para utilizar o software, basta acessar o link http://ururau.ucam-campos.br e efetuar o download de forma gratuita.

O software possibilita a elaboração de modelos de simulação de maneira simples e prática. Em recente artigo, Dagkakis e Heavey (2016) analisaram diversos softwares que possuem aplicação em SED e destacaram aspectos positivos no software Ururau. Os autores citaram, por exemplo, a interface gráfica, que facilita a elaboração de modelos, os vídeos tutoriais, que ajudam os iniciantes a utilizá-lo, e os resultados dos modelos do Ururau, que vêm sendo comparados com resultados de softwares comerciais.

A Figura 1 mostra a GUI do Ururau, na qual é possível observar a área de trabalho onde os módulos são organizados para a construção dos modelos. Também é possível notar a área onde estão dispostos os diversos módulos. Além disso, é apresentada a janela de edição do módulo "Function", onde os dados sobre o tempo de processamento, nome da função e o identificador (ID) podem ser inseridos. Para construir um modelo de simulação utilizando esta ferramenta basta clicar nos módulos, arrastá-los até a área de trabalho e configurar os parâmetros de cada módulo clicando sobre os mesmos com o botão direito do mouse e acessando o comando "Edit".

Figura 1. Tela do Ururau com um modelo simples e caixa de edição do módulo "Função".

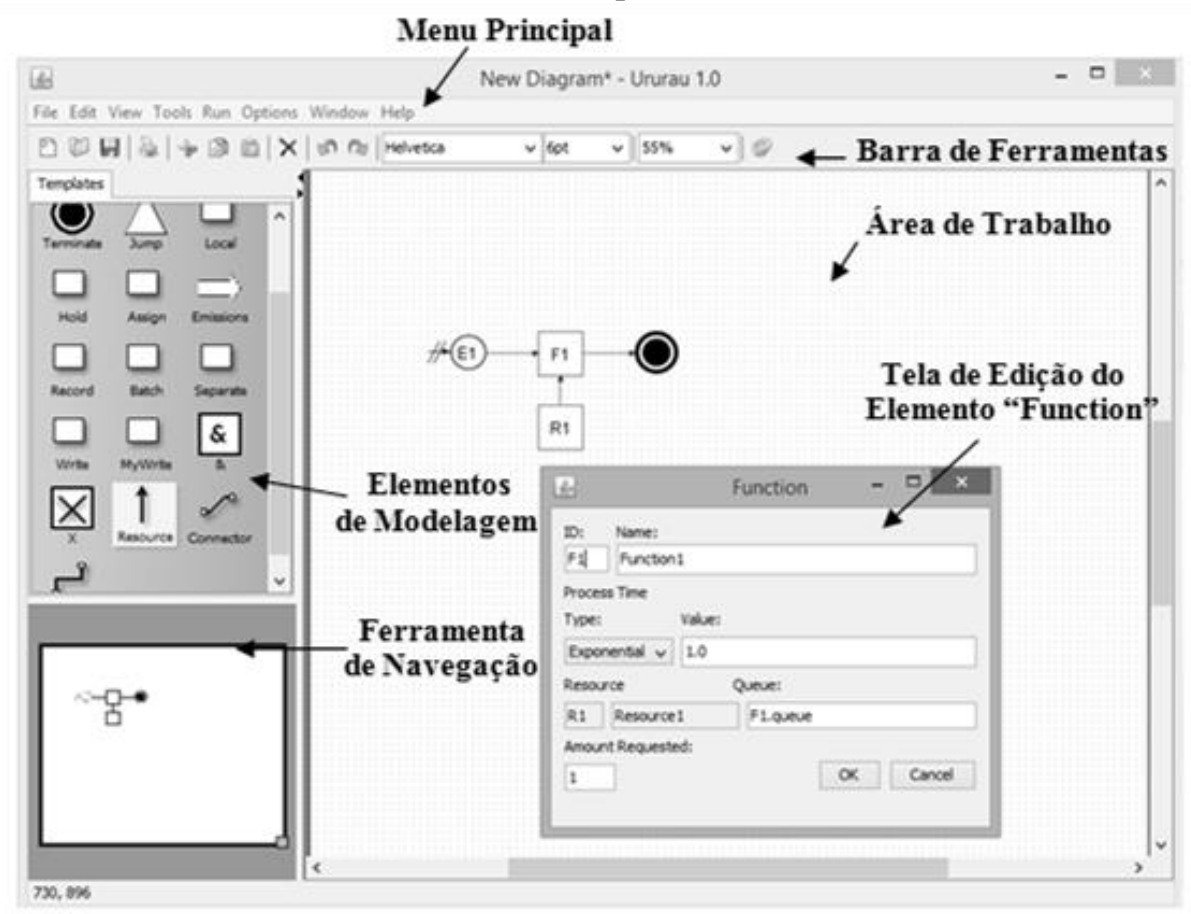

Fonte: Elaborado pelos autores.

Os próximos itens destacam os principais módulos presentes no software Ururau (versão 1.0). Estes módulos permitem ao software possuir um diferencial em relação a outros simuladores semelhantes. Assim, além dos módulos comuns, necessários para a construção dos modelos, é possível também o cálculo de emissões de gases em entidades, a comunicação com Controladores Lógicos Programáveis (CLP), além da utilização de módulos de decisão inteligente com otimizador e Redes Neurais Artificiais (RNA). 


\subsection{Módulo para Cálculo de Emissões de Gases em Entidades}

A versão 1.0 do software permite efetuar o cálculo de emissão de gases das entidades nos modelos, em gCO, por meio do módulo Emissions. A partir deste recurso, é possível desenvolver modelos de sistemas, em que a emissão de gases provenientes dos veículos pode ser computada durante as simulações. Para a utilização do referido módulo, é necessária a inserção de dados como: o nome da variável que acumulará as emissões e os parâmetros para o cálculo (tempo, coeficiente de emissões, potência do motor, carga e peso bruto total do veículo).

Um sistema ilustrativo foi proposto para demonstrar como o novo módulo Emissions facilita o cálculo de emissões no Ururau. Este sistema, o seu modelo computacional, a fórmula utilizada para o cálculo das emissões e a janela de edição do módulo Emissions podem ser observados na Figura 2 nos itens 1, 2, 3 e 4, respectivamente.

Figura 2. 1- Sistema proposto para demonstrar o módulo Emissions; 2- Modelo computacional do sistema proposto; 3- Fórmula utilizada no módulo Emissions; 4- Janela de edição do módulo

Emissions.

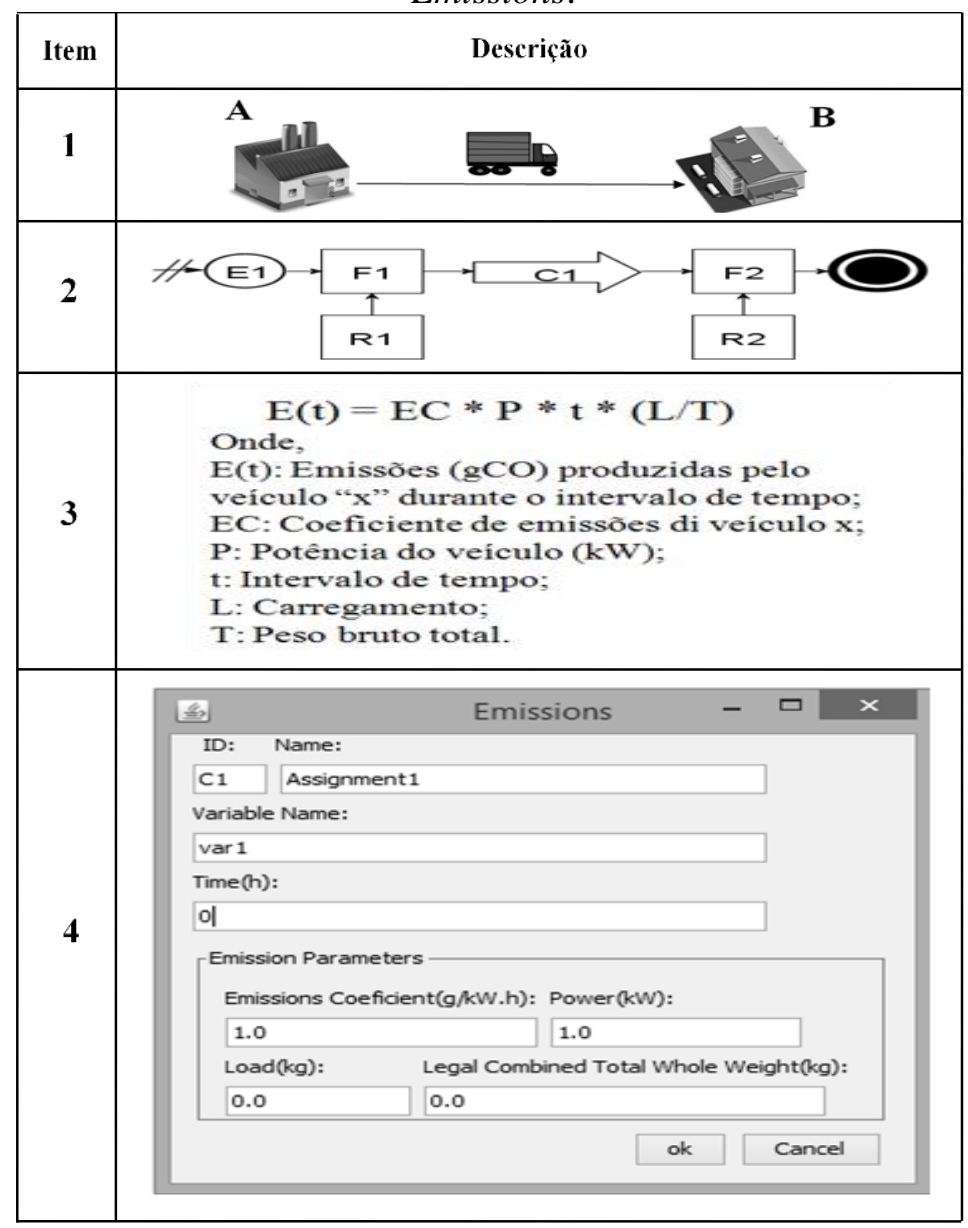

Fonte: Elaborado pelos autores.

Um simples sistema é apresentado no item 1 da Figura 2. Este sistema consiste em entregas que devem ser feitas partindo da Fábrica A para o Cliente B. Este é um sistema elementar, composto por um ponto de partida e outro de destino apenas. Neste sistema, pretende-se ilustrar o mecanismo de cálculo das emissões durante a movimentação dos veículos do ponto A até o ponto B. O cálculo de emissões é feito com o módulo Emissions.

O modelo computacional desse sistema está no item 2 da Figura 2. Nele, o módulo E1 é o gerador de entidades, no caso caminhões. O processo de carregamento na fábrica é feito pelo 
módulo F1 junto com a equipe de carregamento representada por R1. Tudo que envolve o cálculo de emissões e o transporte das entidades da fábrica ao cliente é englobado pelo módulo Emissions, representado por C1. Por último, F2 é o descarregamento dos caminhões no cliente com R2 como a equipe de descarregamento.

A fórmula base descrita pode ser vista no item 3 da Figura 2. Além disso, nesta Figura, também é possível observar a janela de edição do módulo Emissions no item 4. Esta janela permite a inserção dos valores dos parâmetros para o cálculo das emissões.

O módulo Emissions foi fundamentado pelo trabalho de Rangel e Cordeiro (2015). Em seu estudo os autores demonstram como cálculos de emissões de gases do efeito estufa provenientes do transporte em sistemas logísticos podem ser analisados em modelos de simulação a eventos discretos. A fórmula utilizada no módulo Emissions é a mesma utilizada no trabalho citado e é descrita de forma mais detalhada no trabalho de Zhou e Kuhl (2011). Esta expressão calcula o total de emissões, em gramas de $\mathrm{CO}$, produzidas por um veículo durante um determinado percurso. $\mathrm{O}$ resultado das emissões é obtido por meio da multiplicação entre três fatores: o coeficiente de emissões, a potência e o tempo de trajeto do veículo. Os mesmos autores em seu trabalho, ajustaram a fórmula adicionando um outro fator a ser multiplicado pelo resultado anterior. Este é obtido mediante a divisão entre a carga e o peso bruto total do veículo.

\subsection{Módulo para a Comunicação com Controladores Lógicos Programáveis}

O software Ururau também permite a comunicação com CLPs atuando como um simulador para testes de linhas ou plantas produtivas, como demonstra o trabalho de Cardoso et al. (2014), que utilizou o Ururau como recurso didático em aulas de sistemas de controle automático. Para realizar a comunicação, o acesso pode ser feito por intermédio do menu Ferramentas e opção Tools - Communications. Deve-se então marcar a opção de Enable OPC (OLE for Process Control) Communication. OPC é um padrão de interface de software que permite aos programas do Windows se comunicarem com dispositivos de hardware industriais. É necessário criar uma conta de usuário do Windows com permissões de acesso utilizadas para componentes DCOM do servidor OPC escolhido. A comunicação será bem-sucedida quando, clicando em 'Connect', a caixa de texto listar as tags predefinidas no servidor OPC selecionado como mostrado na Figura 3.

Figura 3. Tela de comunicação com CLP do Ururau.

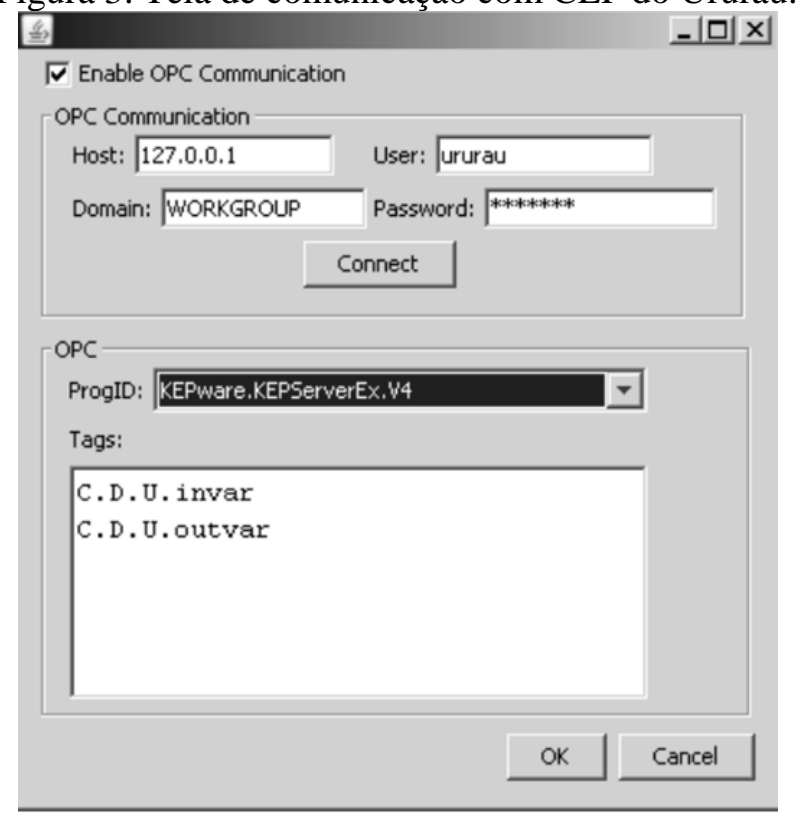

Fonte: Elaborado pelos autores. 


\subsection{Otimização}

O software Ururau permite ainda resolver problemas que envolvam maximização e minimização por meio do módulo otimizador que utiliza algoritmos genéticos.

A Figura 4 apresenta a tela de acesso para entrada de dados no módulo otimizador do software Ururau. Esta tela possibilita a inclusão de variáveis para controlar este módulo dentro do modelo. No caso específico deste software, os valores precisam ser números inteiros. Em "Objective" deve ser colocada a função objetivo, também chamada de função de avaliação do AG. Esta função normalmente é elaborada com as variáveis de resposta, que podem ser número na fila, tempo na fila ou contadores. Pode ser observado, na Figura 4, que o item "is Minimizing? "está habilitado, portanto o módulo otimizador buscava minimizar o resultado da função objetivo neste exemplo. Porém vale ressaltar que o default é maximizar a função objetivo. Para rodar o modelo de forma adequada, quanto se utiliza o módulo otimizador, o mesmo deve ser executado por meio do caminho "Run", presente no "Main Menu" e "Go With Optimizer".

Figura 4. Caixa de otimização no Ururau.

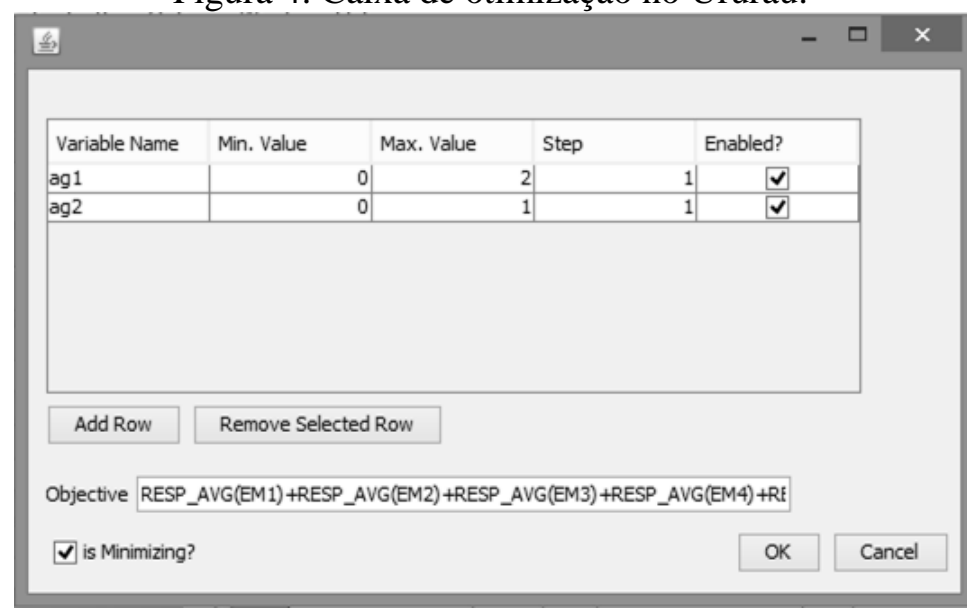

Fonte: Elaborado pelos autores.

O uso de AGs no contexto da simulação a eventos discretos é uma área consolidada na literatura e há diversos estudos sobre o tema. Como, por exemplo, o trabalho de Can et al. (2008), em que os autores utilizaram AG e DES para resolver problemas de alocação de buffer em uma linha de produção. Em outro trabalho, Ponsignon e Mönch (2014) apresentam uma estrutura baseada em simulação que permite a modelagem do comportamento da demanda do mercado e do sistema de produção. Estes autores utilizam heurísticas, entre elas o AG, para avaliar o planejamento mestre da produção de semicondutores em um horizonte de tempo.

\subsection{Decisão com Redes Neurais Artificiais}

Além dos módulos de emissões, comunicação com CLP e otimizador, o software Ururau também possui um módulo específico para decisão com RNA. Segundo Ludwig e Costa (2007), as RNAs baseiam-se em redes neurais biológicas, onde o neurônio recebe um ou mais sinais de entrada, processa e fornece um sinal de saída. Esta saída pode ser tanto uma nova entrada para outro neurônio ou a saída da rede como um todo. Ainda segundo os autores as redes são instrumentos de processamento paralelo, pois recebem simultaneamente os sinais de entrada. A Figura 5 mostra a caixa de edição dos parâmetros para o módulo de decisão com RNA no Ururau. 
Figura 5. Caixa de edição dos parâmetros do RNA no Ururau.

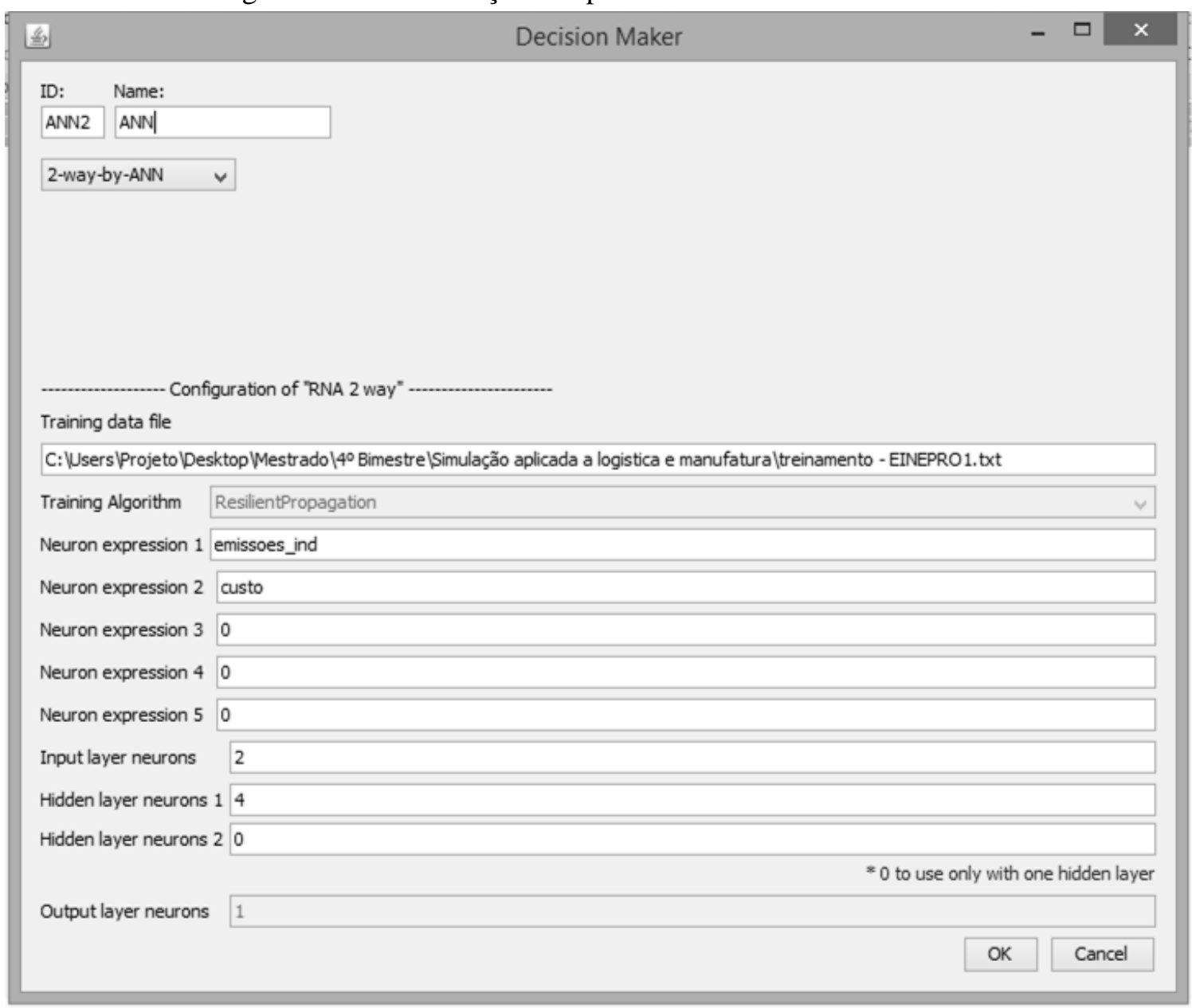

Fonte: Elaborado pelos autores.

Na caixa de edição apresentada na Figura 5, é possível definir a quantidade de neurônios na camada de entrada (de 1 até 5), alocar variáveis ou expressões nos neurônios de entrada, optar por uma ou duas camadas ocultas, escolher o número de neurônios nas camadas ocultas e passar o arquivo de treinamento para a rede. Vale ressaltar que é permitido somente 1 neurônio na camada de saída.

A simulação em conjunto com RNA já foi utilizada no Ururau, como no trabalho de Silva et al. (2015), onde os autores compararam diferentes bibliotecas de RNAs e verificaram seus desempenhos a fim de acoplar o mais adequado ao código do Ururau.

\section{Descrição do Sistema}

O problema objeto de estudo se refere a um sistema logístico de uma fábrica hipotética localizada no estado da Flórida, nos Estados Unidos da América (local escolhido por ser mundialmente conhecido). Na hipótese em questão, os seguintes itens são considerados:

- A empresa deve tomar decisões quanto à escolha do fornecedor mais adequado às suas necessidades;

- A empresa ora dá ênfase a questões ambientais, ora ênfase à produtividade e aos aspectos ambientais. Assim, as emissões e os custos dos fornecedores têm pesos 
diferentes na decisão da fábrica dependendo de sua política quanto aos aspectos ambientais; e

- A escolha do fornecedor mais adequado é tomada com base no custo médio e nas emissões de gases provenientes de cada entrega. O módulo de decisão com RNA classifica cada entrega dos fornecedores em aprovadas ou reprovadas, dependendo da relação entre essas emissões e os custos. O módulo otimizador, então, escolhe o melhor fornecedor com base no número de aprovações dos fornecedores gerados pelo módulo de decisão com RNA. Portanto, o melhor fornecedor é aquele que maximiza o número de aprovações das entregas.

A Figura 6 ilustra a relação entre as fábricas e os fornecedores. O Quadro 1 apresenta a legenda desta Figura.

Figura 6. Relação entre fábricas e fornecedores.

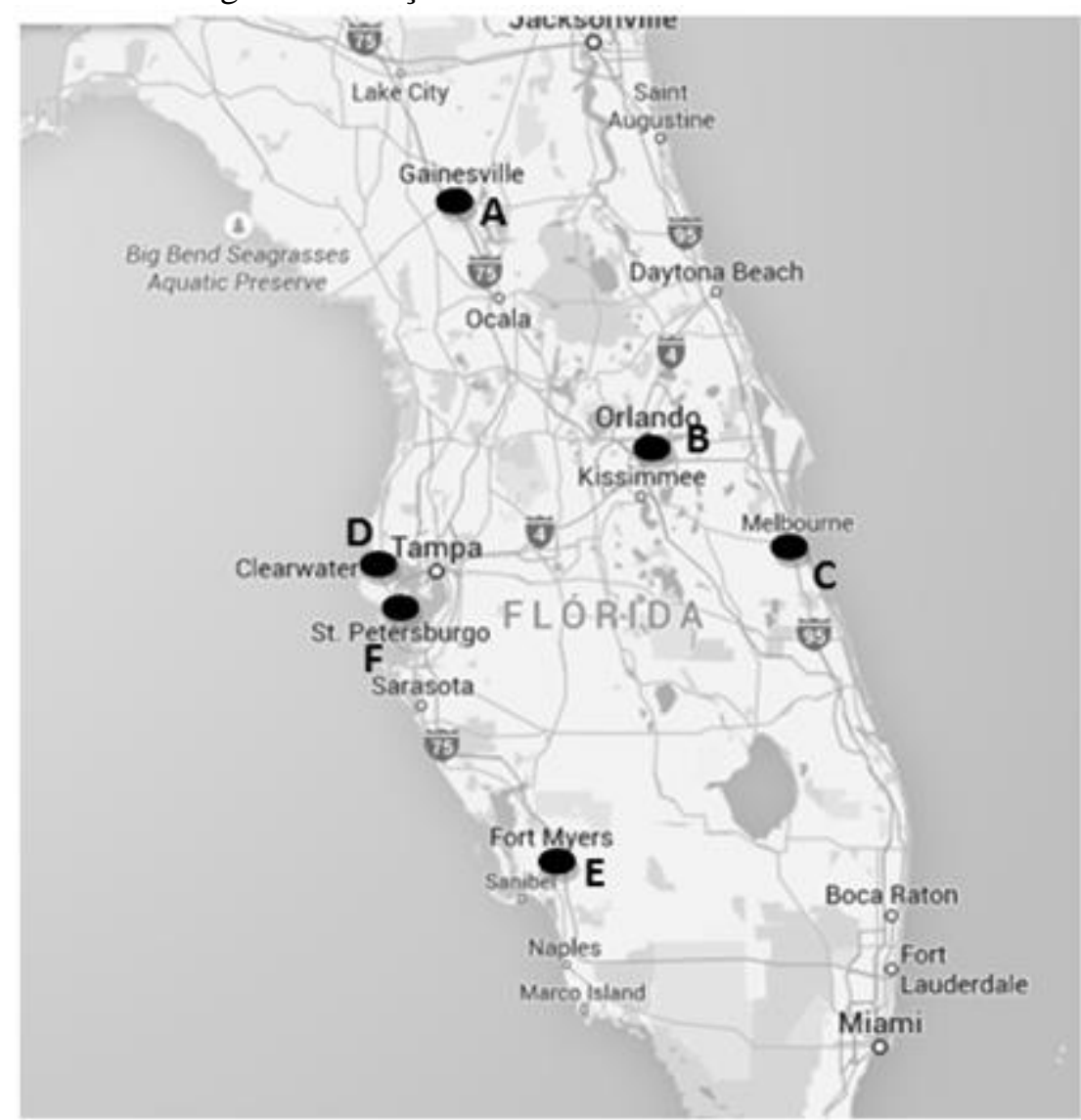

Fonte: Adaptado de www.google.com.br/maps.

Quadro 1. Legenda da Figura 6.

\begin{tabular}{|c|c|c|c|c|}
\hline Legenda & Localização & $\begin{array}{c}\text { Ponto de referência } \\
\text { no mapa }\end{array}$ & $\begin{array}{c}\text { Distância até } \\
\text { a fábrica }\end{array}$ & $\begin{array}{c}\text { Tempo } \\
\text { médio }\end{array}$ \\
\hline Fornecedor 1 & Gainesville/FL & Ponto A & $245 \mathrm{~km}$ & $15 \mathrm{~h}$ \\
\hline Fornecedor 2 & Orlando/FL & Ponto B & $171 \mathrm{~km}$ & $12 \mathrm{~h}$ \\
\hline Fornecedor 3 & Melbourne/FL & Ponto C & $270 \mathrm{~km}$ & $9 \mathrm{~h}$ \\
\hline Fornecedor 4 & Clearwater/FL & Ponto D & $36 \mathrm{~km}$ & $2 \mathrm{~h}$ \\
\hline Fornecedor 5 & Fort Myers/FL & Ponto E & $182 \mathrm{~km}$ & $7 \mathrm{~h}$ \\
\hline Fábrica 1 & St. Petersburgo/FL & Ponto F & - & - \\
\hline
\end{tabular}

Fonte: Elaborado pelos autores.

As distâncias apresentadas no Quadro 1 representam os menores percursos entre os 
fornecedores e a fábrica por meio de rodovias. Estas medidas foram obtidas por intermédio do Google Maps, assim como o tempo de trajeto. Os tempos médios de transporte apresentados são os tempos que cada fornecedor leva para efetuar uma entrega.

Diferentes cenários foram propostos para analisar o comportamento do modelo, em que:

- Foi investigado qual seria o melhor fornecedor para a fábrica com ênfase nas emissões de gases; e

- Depois, foi analisado qual o melhor fornecedor, dando pesos iguais às emissões e aos custos;

Assim, a estrutura do problema proposto busca avaliar dois pontos. Primeiro, verificar se a decisão foi feita de forma correta quanto à escolha dos fornecedores pelo software. Ou seja, os parâmetros de cada fornecedor foram estabelecidos de maneira que fosse mais fácil identificar qual deles é o mais adequado em relação às emissões de gases. E segundo, testar o módulo de decisão inteligente com RNA do software em uma situação mais complexa, em que os pesos de emissões gasosas e os custos fossem mais equivalentes durante a decisão.

\section{Modelo de Simulação}

A metodologia proposta por Banks et al. (2010) foi utilizada para o desenvolvimento dos modelos de simulação. Esta metodologia propõe os seguintes passos: formulação e análise do problema; construção do modelo conceitual; construção do modelo de simulação; verificação e validação; experimentação e interpretação; e análise estatística dos resultados. Durante as fases de verificação e validação dos modelos de simulação, foram observadas as etapas sugeridas por Sargent (2013).

Foram modelados diferentes cenários a partir do sistema proposto. Assim, a diferença entre os cenários foi a quantidade de fornecedores. Isto foi feito para testar o módulo de decisão com RNA e a escolha do módulo otimizador do Ururau. Os cenários modelados englobam de dois a cinco fornecedores no total. Embora, nessa decisão, este número seja pequeno, a lógica a ser testada leva em consideração duas variáveis de cada fornecedor, ou seja, 10 parâmetros diferentes. A RNA e o otimizador normalmente são utilizados para problemas com um número maior de parâmetros para serem analisados, porém, para efeito de comparação com a lógica booleana, optou-se por um problema com menos variáveis. Além disso, o software, por estar em fase embrionária, ainda não suporta grandes configurações envolvendo os módulos de otimização e decisão inteligente com RNA.

A Figura 7 mostra o modelo com a fábrica e os fornecedores, onde a fábrica deve escolher entre um dos fornecedores. Foi utilizada a linguagem IDEF-SIM descrita em Montevechi et al. (2010) para documentar o modelo. Esta mesma linguagem é utilizada no ambiente de desenvolvimento dos modelos no software Ururau.

A escolha dos fornecedores foi baseada nas emissões e custos gerados. Nesta Figura, é possível observar uma numeração que identifica o arranjo de cada um dos cenários e as respectivas partes referentes no modelo de simulação. Todos os cenários têm o item número 5 em comum, que é onde se encontra a decisão sobre os fornecedores. Portanto, por exemplo, o cenário composto pelos números 1 e 5 representa a fábrica tendo que escolher entre dois fornecedores. Com 1, 2 e 5, a fábrica com três fornecedores e assim sucessivamente. Para cada cenário, foi testado o módulo de decisão do item 5 ora com lógica booleana, ora com RNA. Quando foi utilizado o módulo com lógica booleana, a decisão baseou-se somente nas emissões. Quando se aplicou o módulo com RNA, a decisão se apoiou tanto nos custos quanto nas emissões de gases, com peso maior nas emissões nos testes preliminares e com peso igual entre emissões e custos nos experimentos com RNA. Isto foi feito para demonstrar que o módulo de decisão com RNA é normalmente utilizado em situações complexas, quando a modelagem com módulo de decisão por lógica é difícil ou mesmo inviável.

O módulo E1 é responsável pela geração das entidades; nele, as entidades são inseridas no modelo a cada 1 hora. Em seguida, está o módulo onde o otimizador atua, identificado com o $X$. Neste ponto, o módulo otimizador escolhe por onde o fluxo de entidades vai passar. Esse controle é feito por meio da variável "ag"; esta assume um valor entre 1, 2, 3, 4 e 5, que 
representam os diferentes caminhos possíveis. Esses caminhos representam os fornecedores. A decisão de escolha por um deles é norteada pela função objetivo do módulo otimizador. Nesse caso, essa função busca maximizar as aprovações das entregas. Os módulos F1, F3, F5, F7 e F9 são funções que representam o carregamento dos caminhões nos fornecedores, e R1, R3, R5, R7 e R9 representam as equipes de carregamento. Os módulos EM1, EM2, EM3, EM4 e EM5 reproduzem a movimentação dos caminhões dos fornecedores até a fábrica, eles também efetuam o cálculo de emissões totais de cada fornecedor. Na sequência, estão os módulos F2, F4, F6, F8 e F10, que são funções de descarregamento dos caminhões na fábrica e R2, R4, R6, R8 e R10, que são as equipes de descarregamento. Os módulos C1, C4, C7, C10 e C13 são responsáveis por calcular os custos das entregas dos fornecedores. Os módulos C2, C5, C8, C11 e C14 contam as entidades, e C3, C6, C9, C12 e C15 calculam as emissões por entrega. O módulo com o "\&" conecta o fluxo, e A1 faz um "salto" até o outro A1. Logo após o segundo A1, está o módulo onde opera a decisão referente à aprovação ou reprovação das entregas. Esta classificação tem como base as emissões de gases de cada entrega e o custo de cada uma, ora feita por lógica, ora por RNA. Os módulos C13 e C14 fazem a contagem das entregas aprovadas e reprovadas respectivamente.

Figura 7. Modelo de simulação que representa os fornecedores A, B, C, D e E, a fábrica F.

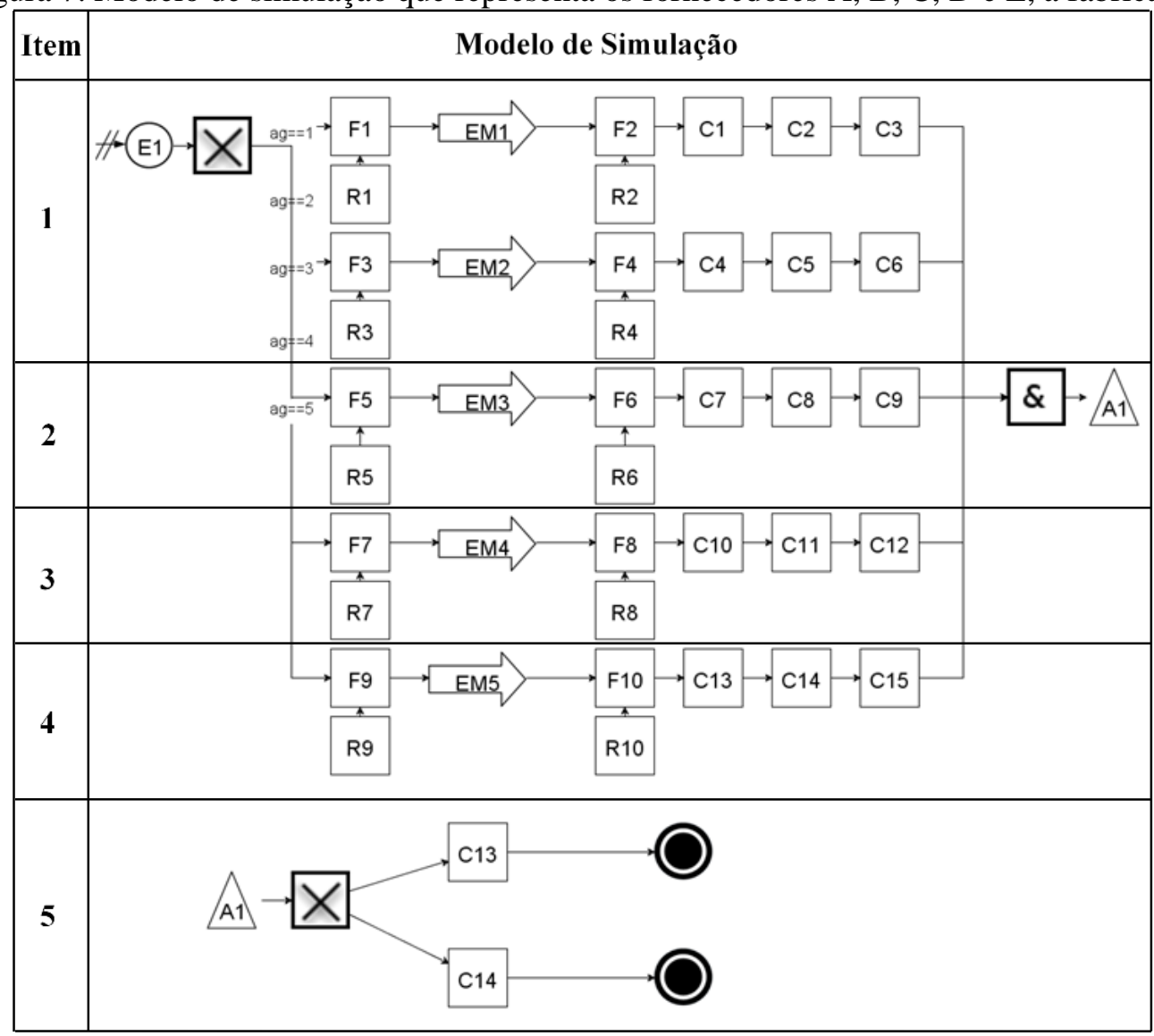

Fonte: Elaborado pelos autores.

Os parâmetros detalhados de cada módulo podem ser observados no Apêndice A. No que se refere ao tempo do percurso e aos custos, foram adotadas funções normais para representar o seu comportamento. As médias dos custos foram arbitradas para serem inversamente proporcionais ao tempo de entrega. Os desvios padrões adotados para as funções de distribuição relativas aos deslocamentos e aos custos foram também estabelecidos em $10 \%$ das médias obtidas no Quadro 1. 


\section{Experimentos Simulados}

Os modelos de simulação apresentados neste trabalho foram executados em uma máquina Dell Inspiron com processador Intel ${ }^{\circledR}$ Core $^{\mathrm{TM}}$ i3-4130 CPU@3,4GHz e sistema operacional Windows 8.1 64bits.

As rodadas dos experimentos no simulador foram feitas com 50 replicações. Para chegar a esse número, foram executadas sucessivas simulações do cenário com os fornecedores A e B e a fábrica $\mathrm{F}$, a fim de monitorar o comportamento das variáveis de resposta a cada incremento do número de replicações.

Cada uma das rodadas de simulação foi executada com $720 \mathrm{~h}$, equivalente ao período de 30 dias com turnos de 24 horas. O tempo de processamento para as rodadas de simulação dos modelos foram de, aproximadamente, 20 minutos. Vale ressaltar que, sem os módulos de decisão com otimizador e RNA, esse tempo cai para, aproximadamente, 1 minuto. Isso se deve principalmente ao tempo gasto no treinamento da RNA e também ao tempo usado por cada entidade para percorrer a lógica da rede neural.

$\mathrm{O}$ arquivo de treinamento foi criado com números aleatórios atribuídos pela própria simulação. As variáveis de interesse para a criação desse conjunto foram as emissões e custos gerados das entregas realizadas por cada fornecedor. Assim, foi executado o modelo de simulação sem o módulo de decisão, com a intenção de captar os valores das variáveis de interesse. Estes valores foram gravados em um arquivo de texto, pelo módulo Write do Ururau, que salvou os números gerados pelas variáveis de emissão e custos para cada entidade criada na simulação durante as replicações. Então, os valores das variáveis foram copiados para uma planilha eletrônica, na qual foram estabelecidos critérios para a aprovação e reprovação das entidades com base no valor dessas variáveis. A estratégia utilizada para determinar os critérios foi arbitrária, determinando-se um limite para o custo e a emissão; caso um dos valores superasse essa faixa, a entrega era reprovada. Dado a reprovação de uma entidade atribui-se o valor zero e aprovação o valor um. Por fim, o arquivo foi convertido para o formato .txt e o diretório foi indicado no módulo de decisão com RNA do software no campo "Training data file", conforme pode ser observado na Figura 5. Cabe ressaltar que o treinamento é executado apenas uma vez pelo software antes das replicações da simulação.

\subsection{Testes Preliminares}

Para a realização dos experimentos simulados, primeiro foram executadas as simulações de cada um dos fornecedores. Isto foi feito para que fossem medidas as variáveis usadas como parâmetros para a decisão nos modelos, que são: as emissões por entidade e o custo médio das entregas. A Figura 8 mostra estas variáveis em relação a cada fornecedor.

A escolha da localização das cidades foi realizada de forma a demonstrar a capacidade do software em apresentar os resultados óbvios esperados para uma situação específica. Por exemplo, quando a escolha estiver entre o fornecedor A e o fornecedor B, e o foco forem as emissões, o fornecedor B deve ser o escolhido, pois apresenta menor emissão de gases. As emissões estão relacionadas com a distância entre os fornecedores e a fábrica; quanto menor a distância, menor a emissão de gases.

Da mesma forma, a Figura 8 também apresenta o custo médio de cada um dos fornecedores (Figura 6 e Quadro 1). Assim, o custo médio foi maior para o fornecedor D, localizado na cidade de Clearwater/FL, com 1485,69 u.m., sendo este o escolhido caso o foco da decisão sejam apenas as emissões.

A Figura 8 ilustra ainda que os custos são inversamente proporcionais às emissões. Os parâmetros de emissões e custos foram adotados desta forma para que os resultados dos testes preliminares fossem óbvios. Assim, foi possível determinar se o software Ururau estava respondendo corretamente de acordo com a lógica do sistema proposto.

Após esta etapa, foram feitas as simulações dos cenários conforme o modelo mostrado na Figura 7, onde cada cenário foi simulado com diferentes arranjos de fornecedores. A Tabela 1 mostra os resultados dessas simulações. Nela, podem-se observar os cenários, o grupo de 
fornecedores utilizados em cada cenário, o tipo de decisão que foi usada e os parâmetros do fornecedor escolhido. Desta forma, os parâmetros do fornecedor escolhido englobam: as emissões totais, emissões por entidades e o custo médio das entregas.

Figura 8. Emissões por entidade e custo médio de entrega dos fornecedores A, B, C, D e E em $\mathrm{gCO}$.

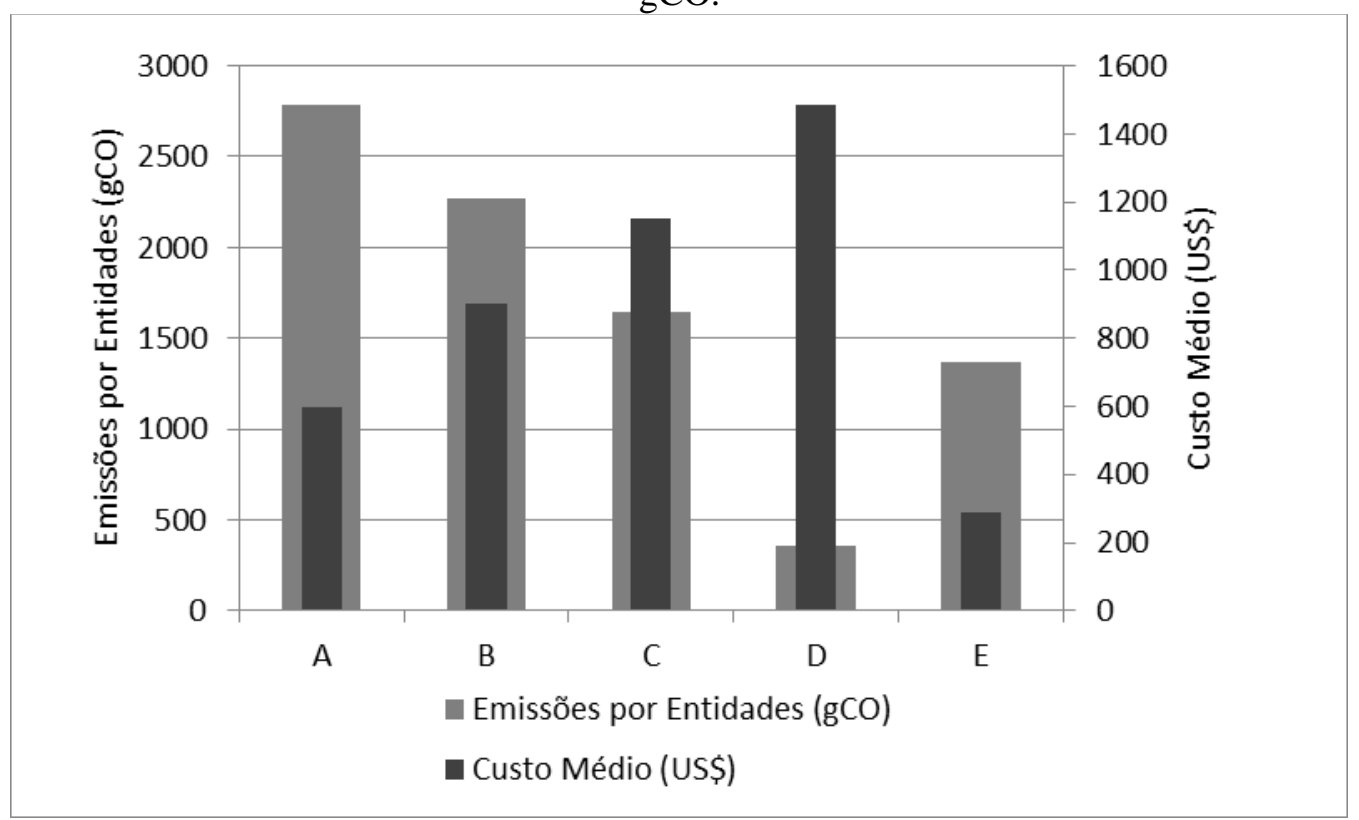

Fonte: Elaborado pelos autores.

Tabela 1. Cenários, fornecedores utilizados em cada cenário, tipo de decisão usada, fornecedor escolhido, emissões totais e por entidades, custo médio.

\begin{tabular}{|c|c|c|c|c|c|c|c|c|c|}
\hline هి. & 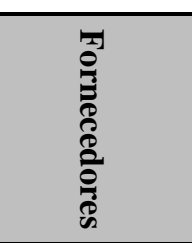 & 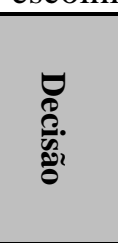 & 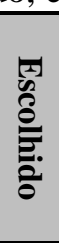 & 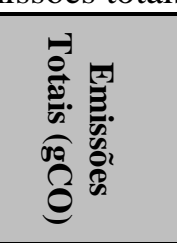 & 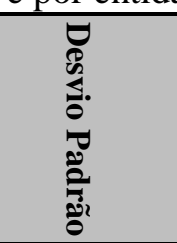 & 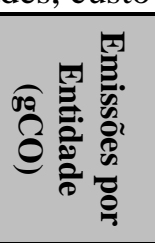 & 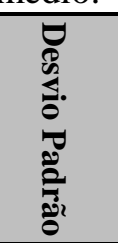 & 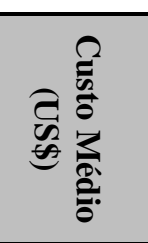 & 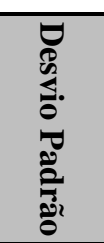 \\
\hline \multirow{2}{*}{1} & \multirow{2}{*}{$\mathrm{A}$ e B } & Lógica & \multirow{2}{*}{ B } & \multirow{2}{*}{$318.041,55$} & \multirow{2}{*}{$12.406,033$} & \multirow{2}{*}{$2.266,64$} & \multirow{2}{*}{33,591} & \multirow{2}{*}{901,71} & \multirow{2}{*}{18,367} \\
\hline & & RNA & & & & & & & \\
\hline \multirow{2}{*}{2} & \multirow{2}{*}{$\mathrm{A}, \mathrm{B}$ e $\mathrm{C}$} & Lógica & \multirow{2}{*}{$\mathrm{C}$} & \multirow{2}{*}{$231.500,58$} & \multirow{2}{*}{$9.251,295$} & \multirow{2}{*}{$1.642,226$} & \multirow{2}{*}{27,453} & \multirow{2}{*}{$1.150,27$} & \multirow{2}{*}{73,788} \\
\hline & & RNA & & & & & & & \\
\hline \multirow{2}{*}{3} & \multirow{2}{*}{$\mathrm{A}, \mathrm{B}, \mathrm{C}$ e $\mathrm{D}$} & Lógica & \multirow{4}{*}{ D } & \multirow{4}{*}{$50.885,03$} & \multirow{4}{*}{$1.995,101$} & \multirow{4}{*}{357,393} & \multirow{4}{*}{5,491} & \multirow{4}{*}{$1.485,69$} & \multirow{4}{*}{174,78} \\
\hline & & RNA & & & & & & & \\
\hline \multirow{2}{*}{4} & \multirow{2}{*}{$\mathrm{A}, \mathrm{B}, \mathrm{C}, \mathrm{D}$ e $\mathrm{E}$} & Lógica & & & & & & & \\
\hline & & RNA & & & & & & & \\
\hline
\end{tabular}

Fonte: Elaborado pelos autores.

Além disso, a Tabela 2 apresenta o número de entidades que trafegaram no sistema e a quantidade de entregas aprovadas e reprovadas pela fábrica também referentes ao fornecedor escolhido.

Nas Tabelas 1 e 2, as decisões com a lógica booleana levaram em consideração somente as emissões por entidade dos fornecedores. Já as decisões com o módulo de decisão com RNA, além das emissões, também consideraram os custos. Nesta etapa, porém, a decisão do módulo com RNA dava maior ênfase às emissões, ou seja, a decisão com inteligência computacional 
dava maior prioridade, ou peso, para as emissões do que para os custos, neste caso. Isto foi feito para mostrar que a decisão com o módulo com RNA está sendo feita de forma correta pelo software, uma vez que tanto a decisão com lógica quanto com o módulo RNA apontaram a mesma escolha. Assim, é possível observar que a eleição dos fornecedores está condizente com a lógica, ou seja, sempre foi selecionado o fornecedor com a menor emissão de gases.

Tabela 2. Cenários, fornecedores utilizados em cada cenário, tipo de decisão usada, fornecedor escolhido, número de entidades totais, número de aprovados e reprovados.

\begin{tabular}{|c|c|c|c|c|c|c|c|c|c|}
\hline 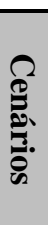 & 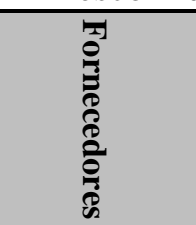 & 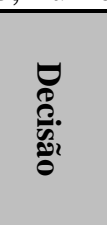 & 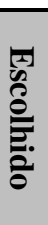 & 即 & 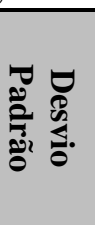 & $\begin{array}{l}\frac{D}{0} \\
0 \\
0 \\
0 \\
0 \\
0 \\
0\end{array}$ & 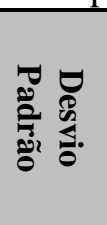 & 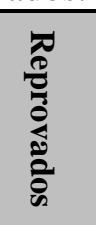 & 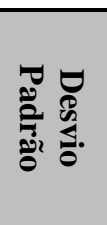 \\
\hline \multirow{2}{*}{1} & \multirow{2}{*}{$A$ e B } & Lógica & \multirow{2}{*}{ B } & \multirow{2}{*}{139,6} & \multirow{2}{*}{4,891} & 96,26 & 11,095 & 43,34 & 12,412 \\
\hline & & RNA & & & & 124,96 & 5,664 & 14,64 & 4,198 \\
\hline \multirow{2}{*}{2} & \multirow{2}{*}{$A, B$ e $C$} & Lógica & \multirow{2}{*}{$\mathrm{C}$} & \multirow{2}{*}{140,24} & \multirow{2}{*}{5,004} & 116,14 & 7,618 & 24,1 & 7,678 \\
\hline & & RNA & & & & 129,78 & 5,762 & 10,46 & 3,693 \\
\hline \multirow{2}{*}{3} & \multirow{2}{*}{$\mathrm{A}, \mathrm{B}, \mathrm{C}$ e $\mathrm{D}$} & Lógica & \multirow{4}{*}{$\mathrm{D}$} & \multirow{4}{*}{141,76} & \multirow{4}{*}{4,984} & 131,9 & 6,434 & 9,86 & 4,936 \\
\hline & & RNA & & & & 124,1 & 6,122 & 17,66 & 5,531 \\
\hline \multirow{2}{*}{4} & \multirow{2}{*}{ A,B,C,D e E } & Lógica & & & & 131,9 & 6,434 & 9,86 & 4,936 \\
\hline & & RNA & & & & 126,66 & 6,009 & 15,1 & 5,132 \\
\hline
\end{tabular}

Fonte: Elaborado pelos autores.

Alguns parâmetros têm valores repetidos nas Tabelas 1 e 2. Isso se dá pela escolha do mesmo fornecedor como sendo o mais adequado tanto no uso da lógica quanto no uso da RNA. No entanto, a quantidade de aprovações e reprovações se alterou conforme se alternava o tipo de decisão usada. Em sistemas com uma lógica de maior complexidade, o módulo com a RNA pode facilitar a construção do modelo, permitido modelar decisões com maior número de detalhes, por exemplo, se mais fornecedores e mais variáveis, além das emissões e custos, forem considerados, ou ainda se a tomada de decisão não se basear em uma lógica clara.

\subsection{Experimentos com RNA}

Após a etapa dos testes preliminares, foram feitas as simulações dos cenários adotando peso igual para as emissões de gases e custos das entregas, aumentado, assim, a complexidade das decisões. Nesta etapa, somente a decisão inteligente com o módulo RNA foi utilizada para aprovar ou reprovar as entregas, uma vez que foi comprovada a correta classificação feita por este módulo. Ou seja, para o problema apresentado neste trabalho a RNA mostrou-se compatível com a lógica. Porém sugere-se que, em trabalhos futuros, sejam feitos testes adicionais comparando os resultados da rede com a lógica, incluindo mais variáveis e fornecedores na decisão. Devido a limitações no número de entradas da RNA na versão atual do software Ururau, estes testes não foram executados ainda.

A Tabela 3 apresenta os resultados das simulações conforme o modelo mostrado na Figura 7, onde cada cenário foi simulado com os diferentes arranjos de fornecedores. Nela podem ser observados os mesmos parâmetros da Tabela 1: os cenários, o grupo de fornecedores utilizados em cada cenário e o fornecedor escolhido, as emissões totais, as emissões por entidades e o custo médio das entregas. A exceção é que a Tabela 3 não mostra o tipo de decisão usada, pois, em todos os casos, foi utilizado o módulo de decisão inteligente com RNA.

A Tabela 4, assim como a Tabela 2, apresenta o número total de entidades que trafegaram no sistema e a quantidade de entregas aprovadas e reprovadas pela fábrica referentes ao fornecedor escolhido. Como a Tabela 3, a Tabela 4 não mostra o tipo de decisão usada, pois em todos os casos foi utilizado o módulo de decisão inteligente com RNA. 
Os fornecedores escolhidos nas Tabelas 3 e 4 foram diferentes dos escolhidos na Tabela 1 e 2. Isto se deve a mudança no treinamento do módulo de decisão com RNA, que agora analisa com pesos iguais os parâmetros de emissões de gases e custos médios das entregas. Desta forma, pode ser observado que o fornecedor $\mathrm{E}$ é o melhor fornecedor com o novo treinamento da rede. Por meio das Figuras 8 e 9, nota-se que o fornecedor E possui uma melhor relação entre emissões por entregas e custos médios por entregas do que os demais fornecedores. Quando este fornecedor não está disponível, o fornecedor A foi o escolhido nos demais arranjos de fornecedores.

Tabela 3. Cenários, fornecedores utilizados em cada cenário, fornecedor escolhido, emissões totais e por entidades e custo médio.

\begin{tabular}{|c|c|c|c|c|c|c|c|c|}
\hline هి. & 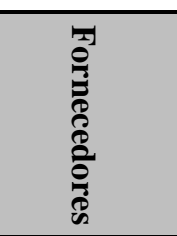 & 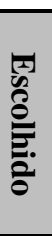 & 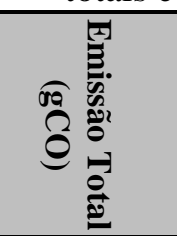 & 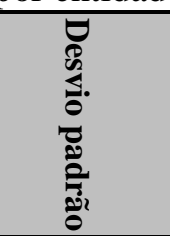 & 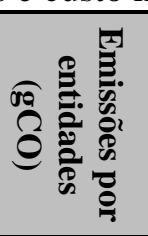 & 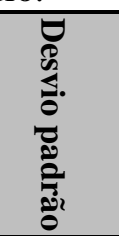 & 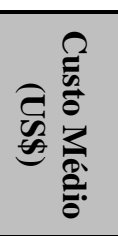 & 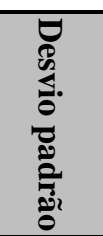 \\
\hline 1 & A e B & \multirow{3}{*}{ A } & \multirow{3}{*}{$393.237,59$} & \multirow{3}{*}{$14.601,203$} & \multirow{3}{*}{$2.812,2$} & \multirow{3}{*}{31,315} & \multirow{3}{*}{616,23} & \multirow{3}{*}{97,417} \\
\hline 2 & $\mathrm{~A}, \mathrm{~B}$ e $\mathrm{C}$ & & & & & & & \\
\hline 3 & $\mathrm{~A}, \mathrm{~B}, \mathrm{C}$ e $\mathrm{D}$ & & & & & & & \\
\hline 4 & $\mathrm{~A}, \mathrm{~B}, \mathrm{C}$ e $\mathrm{E}$ & \multirow{2}{*}{ E } & \multirow{2}{*}{$193.193,16$} & \multirow{2}{*}{$8.960,913$} & \multirow{2}{*}{$1.367,64$} & \multirow{2}{*}{37,223} & \multirow{2}{*}{287,48} & \multirow{2}{*}{61,773} \\
\hline 5 & $A, B, C, D$ e $E$ & & & & & & & \\
\hline
\end{tabular}

Fonte: Elaborado pelos autores.

Tabela 4. Cenários, fornecedores utilizados em cada cenário, fornecedor escolhido, emissões totais e por entidades, custo médio, número de entidades totais, número de aprovados e

\begin{tabular}{|c|c|c|c|c|c|c|c|c|}
\hline @ి & 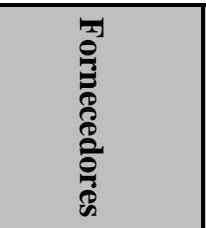 & 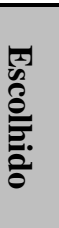 & 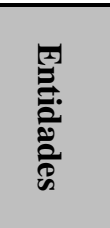 & 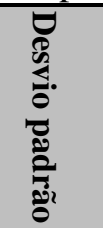 & 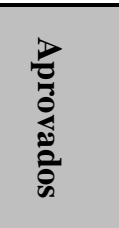 & 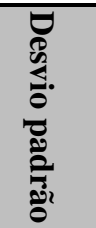 & 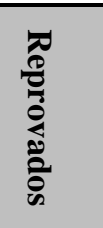 & 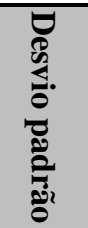 \\
\hline 1 & $\mathrm{~A}$ e B & \multirow{3}{*}{ A } & \multirow{3}{*}{139,08} & \multirow{3}{*}{4,882} & 115,66 & 5,389 & 23,42 & 4,607 \\
\hline 2 & $\mathrm{~A}, \mathrm{~B}$ e $\mathrm{C}$ & & & & 119,3 & 5,523 & 19,78 & 4,532 \\
\hline 3 & $\mathrm{~A}, \mathrm{~B}, \mathrm{C}$ e $\mathrm{D}$ & & & & 118,46 & 5,740 & 20,62 & 4,615 \\
\hline 4 & $\mathrm{~A}, \mathrm{~B}, \mathrm{C}$ e $\mathrm{E}$ & \multirow{2}{*}{ E } & \multirow{2}{*}{140,46} & \multirow{2}{*}{5,035} & 140,26 & 5,022 & 0,2 & 0,404 \\
\hline 5 & $\mathrm{~A}, \mathrm{~B}, \mathrm{C}, \mathrm{D}$ e $\mathrm{E}$ & & & & 140,28 & 5,018 & 0,18 & 0,388 \\
\hline
\end{tabular}

Fonte: Elaborado pelos autores.

Assim como nas Tabelas 1 e 2, alguns parâmetros têm valores repetidos nas Tabelas 3 e 4 nos itens que independem das decisões tomadas nos modelos.

A Figura 9 mostra uma comparação entre os parâmetros dos fornecedores escolhidos com os diferentes treinamentos da rede. Desta forma, são apresentadas as emissões totais e os custos médios dos fornecedores $\mathrm{D}$ e $\mathrm{E}$, que são respectivamente o melhor entre os fornecedores apontado pela rede quando o treinamento focava as emissões gasosas, e o melhor quando o treinamento deu ênfase igual entre as emissões e os custos.

Os resultados dispostos na Figura 9 mostram que as emissões totais e os custos médios dos dois fornecedores escolhidos são quase opostos. Enquanto o fornecedor D possui um melhor desempenho em relação às emissões, o fornecedor E possui custos menores. Isso mostra como diferentes comportamentos de um comprador podem ser emulados com redes neurais artificiais mudando apenas o treinamento da rede. Vale ressaltar que as RNAs são capazes de simular 
comportamentos baseados em inúmeros parâmetros. Assim, em um exemplo real, deve-se considerar uma gama maior de parâmetros para a decisão como: tempo de transporte, confiabilidade das entregas, flexibilidade dos fornecedores, qualidade do material, etc.

Figura 9. Comparação dos parâmetros de emissões totais e custos médios dos fornecedores escolhidos com os diferentes treinamentos da rede.

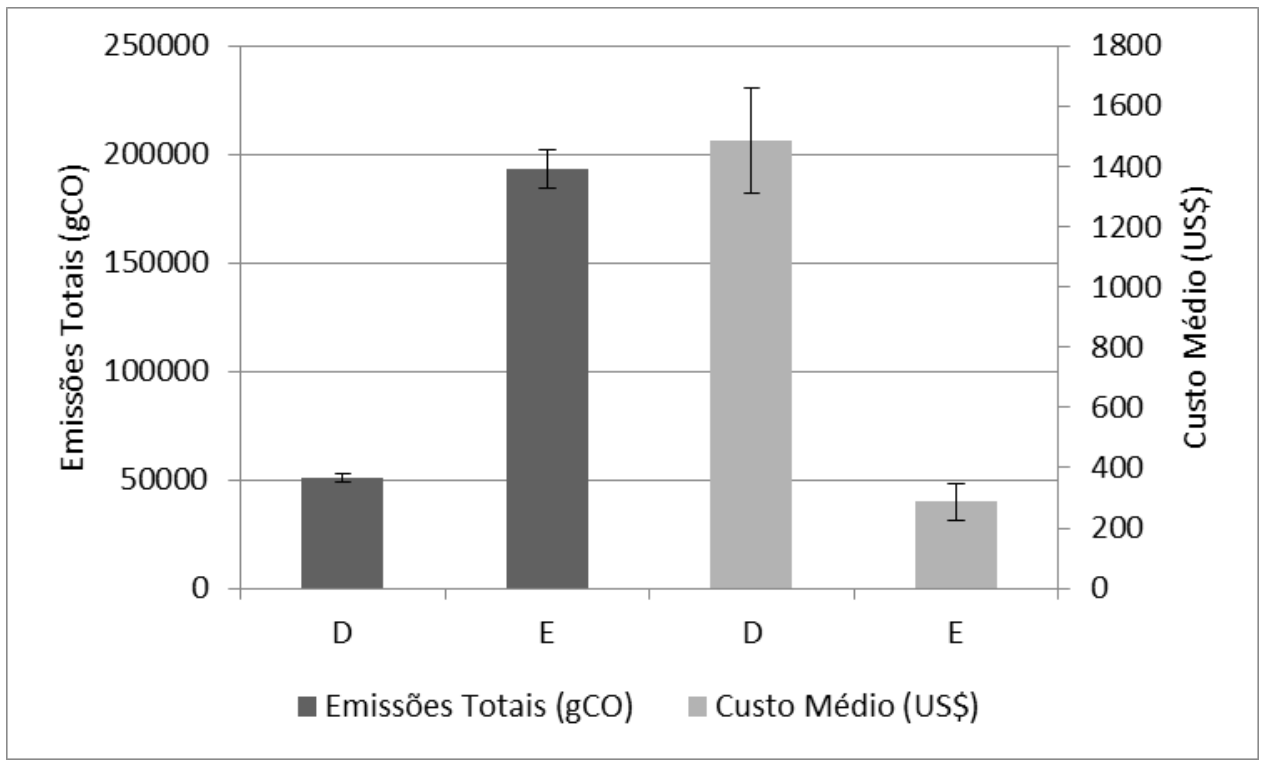

Fonte: Elaborado pelos autores.

\section{Conclusão}

O estudo apresentou uma aplicação do software Ururau envolvendo emissões de gases do efeito estufa com os módulos de cálculo de emissões de gases e decisão com lógica de inteligência computacional. Para isso, foi elaborado um modelo de um sistema logístico hipotético para testar e demonstrar essas funções do software. Para validar os módulos, principalmente a decisão com Redes Neurais Artificiais, estabeleceram-se parâmetros de forma que o melhor resultado executado fosse o óbvio. Assim, os resultados gerados foram analisados para avaliar se estavam dentro do esperado.

Após os testes preliminares apontarem o correto funcionamento do módulo de decisão com a RNA no software Ururau, este foi utilizado em modelos com maior complexidade. Este procedimento permitiu que o modelo pudesse executar a lógica com uma decisão mais "inteligente". Os novos resultados mostram decisões coerentes, ou seja, no mesmo arranjo de fornecedores, a escolha alterou conforme o foco e treinamento da rede.

Estes primeiros resultados envolvendo emprego de modelos de simulação com decisão por meio de algoritmos de inteligência computacional no Ururau mostraram a possibilidade de aplicação deste recurso no software. Além disso, o uso do módulo Emissions possibilitou efetuar o cálculo de emissões de $\mathrm{CO}$ de forma ágil e simples.

Destaca-se ainda que a relação entre emissão de gases e tempo de entrega pode ser uma informação útil no momento da venda de um determinado produto pelas empresas. Ou seja, um consumidor pode ser informado, por exemplo, que a escolha por uma entrega mais rápida do produto comprado pode estar causando maior emissão de gases do efeito estufa durante o transporte da carga. Diante desta informação, um consumidor mais consciente pode optar por esperar um tempo maior pelo produto e tomar, assim, uma decisão mais sustentável para o planeta. 
Agradecimentos. Os autores gostariam de agradecer à Coordenação de Aperfeiçoamento de Pessoal de Nível Superior (CAPES), ao Conselho Nacional de Desenvolvimento Científico e Tecnológico $(\mathrm{CNPq})$ e à Fundação de Amparo à Pesquisa do Estado do Rio de Janeiro (FAPERJ) pelo suporte financeiro para esta pesquisa.

\section{Referências}

Adhitya, A., Halim, I. e Srinivasan, R. Decision support for green supply chain operations by integrating dynamic simulation and LCA indicators: Diaper case study. Environmental Science \& Technology, v. 45, n. 23, p. 10178-10185, 2011.

Banks, J., Carson II, J. S., Barry, N. L. e Nicol, D. M. Discrete-Event System Simulation. $5^{\mathrm{a}}$ ed., Estados Unidos da América: Prentice Hall, 2010.

Bruzzone, A., Fadda, P., Fancello, G., Massei, M., Bocca, E., Tremori, A., Tarone, F. e D'Errico, G. Logistics node simulator as an enabler for supply chain development: innovative portainer simulator as the assessment tool for human factors in port cranes. Simulation, v. 87, n. 10 , p. 857-874, 2011.

Buil, R., Piera, M. A. e Laserna, T. Operational and strategic supply model redesign for an optical chain company using digital simulation. Simulation, v. 87, n. 8, p. 668-679, 2011.

Byrne, P. J., Heavey, C., Ryan, P. e Liston, P. Sustainable supply chain design: capturing dynamic input factors. Journal of Simulation, v. 4, n. 4, p. 213-221, 2010.

Can, B., Beham, A. e Heavey, C. A comparative study of genetic algorithm components in simulation-based optimization. In: Anais da 2008 Winter Simulation Conference, Miami, Florida. IEEE Press, 2008. p. 1829-1837.

Cardoso, L. D., Rangel, J. J. A., Nascimento, A. C., Laurindo, Q. M. G. e Camacho, J. C. Discrete event simulation for teaching in control systems. In: Anais da 2014 Winter Simulation Conference, Savannah, Geórgia. IEEE Press, 2014. p. 3608-3617.

Dagkakis, G. e Heavey, C. A review of open source discrete event simulation software for operations research. Journal of Simulation, v. 10, n. 3, p. 193-206, 2016.

IEA Statistics. CO2 emissions from fuel combustion-highlights. IEA, Paris. Disponível em: <http://www.iea.org/publications/freepublications/publication/ CO2EmissionsFromFuelCombustionHighlights2014.pdf>. Acesso em: 27/02/2014.

Longo, F. Sustainable supply chain design: an application example in local business retail. Simulation, v. 88, n. 12, p. 1484-1498, 2012.

Ludwig, O. e Costa, E. Redes Neurais: Fundamentos e Aplicações com Programas em C. Rio de Janeiro: Editora Ciência Moderna, 2007.

Mattila, T. e Antikainen, R. Backcasting sustainable freight transport systems for Europe in 2050. Energy Policy, v. 39, n. 3, p. 1241-1248, 2011.

Montevechi, J. A. B., Leal, F., Pinho, A. F., Costa, R. F. S., Oliveira, M. L. M. e Silva, A. L. F. Conceptual modeling in simulation projects by mean adapted IDEF: an application in a 
Brazilian tech company. In: Anais da 2010 Winter Simulation Conference, Baltimore, Maryland. IEEE Press, 2010. p. 1624-1635.

Peixoto, T. A., Rangel, J. J. A. e Matias, I. O. Free and open-source simulation software "Ururau". In: Anais da 2014 Winter Simulation Conference, Savannah, Geórgia. IEEE Press, 2014. p. 4097-4098.

Ponsignon, T. e Mönch, L. Simulation-based performance assessment of master planning approaches in semiconductor manufacturing. Omega, v. 46, p. 21-35, 2014.

Rabe, M., Horvath, A., Spieckermann, S. e Fechteler, T. An approach for increasing flexibility in green supply chains driven by simulation. In: Anais da 2012 Winter Simulation Conference, Berlim, Alemanha. IEEE Press, 2012. p. 4673-4781.

Rangel, J. J. A. e Cordeiro, A. C. A. Free and Open-Source Software for sustainable analysis in logistics systems design. Journal of Simulation, v. 9, n. 1, p. 27-42, 2015.

Rossetti, M. D. Java Simulation Library (JSL): An open-source object-oriented library for discrete-event simulation in Java. International Journal of Simulation and Process Modelling, v. 4, n. 1, p. 69-87, 2008.

Sargent, R. G. Verifications and validation of simulations models. Journal of Simulation, v. 7, n. 1, p. 12-24, 2013.

Silva, C., Ross, M. e Farias, T. Analysis and simulation of "low-cost" strategies to reduce fuel consumption and emissions in conventional gasoline light-duty vehicles. Energy Conversion and Management, v. 50, n. 2, p. 215-222, 2009.

Silva, F. F., Tavares, E. R., Peixoto, T. A., Matias, I. O. e Rangel, J. J. A. O uso de inteligência computacional na lógica de decisão em modelos de simulação - Uma aplicação no cálculo de emissões de gases em sistemas logísticos. Pesquisa Operacional para o Desenvolvimento, v. 7, n. 2, p. 228-247, 2015.

Sundarakani, B., Souza, R., Goh, M., Wagner, S. M. e Manikandan, S. Modeling carbon footprints across the supply chain. International Journal of Production Economics, v. 128, n. 1, p. 43-50, 2010.

Zhou, X. e Kuhl, M. E. A sustainability toolkit for simulation: Recent developments and future capabilities. In: Anais da 2011 Winter Simulation Conference, Phoenix, Arizona. IEEE Press, 2011. p. 850-858.

Apêndice A: Módulos do Ururau com descrição e dados de configuração

\begin{tabular}{|c|c|c|c|}
\hline Módulo & Nome & Descrição & Dados de Configuração \\
\hline Create & E1 & $\begin{array}{l}\text { Responsável pela } \\
\text { geração de } \\
\text { entidades. }\end{array}$ & $\begin{array}{l}\text { T. Chegadas: Const. }(1 \mathrm{~h}) \\
\text { T. Prim. Chegada: } 0.0 \mathrm{~h} \\
\text { Máx. Chegadas: Infinity }\end{array}$ \\
\hline $\begin{array}{l}\text { Loading } \\
\text { Process }\end{array}$ & $\begin{array}{c}\text { F1, F3, F5, } \\
\text { F7 and F9 }\end{array}$ & $\begin{array}{c}\text { Executa um } \\
\text { processo }\end{array}$ & $\begin{array}{c}\text { Type: Expression } \\
\text { Value: } \operatorname{NORM}(5,2) \\
\end{array}$ \\
\hline $\begin{array}{l}\text { Unloading } \\
\text { Process }\end{array}$ & $\begin{array}{l}\text { F2, F4, F6, } \\
\text { F8 and F10 }\end{array}$ & $\begin{array}{l}\text { Executa um } \\
\text { processo }\end{array}$ & $\begin{array}{c}\text { Type: Expression } \\
\text { Value: NORM }(4,1.8)\end{array}$ \\
\hline $\begin{array}{l}\text { Resource } \\
\text { Team for }\end{array}$ & $\begin{array}{l}\text { R1, R3, R5, } \\
\text { R7 and R9 }\end{array}$ & $\begin{array}{l}\text { Adiciona um } \\
\text { recurso }\end{array}$ & Capacity 1 \\
\hline
\end{tabular}




\begin{tabular}{|c|c|c|c|}
\hline Loading & & & \\
\hline $\begin{array}{l}\text { Resource } \\
\text { Team for } \\
\text { Unloading }\end{array}$ & $\begin{array}{l}\text { R2, R4, R6, } \\
\text { R8 and R10 }\end{array}$ & $\begin{array}{l}\text { Adiciona um } \\
\text { recurso }\end{array}$ & Capacity 1 \\
\hline Emissions & EM1 & Calcula as emissões & $\begin{array}{c}\text { Variable name: em } \\
\text { Time(h):NORM(15,1.5) } \\
\text { Emissions coeficient: } 1.5 \\
\text { Power: } 136 \\
\text { Load(kg): } 20000 \\
\text { Legal Combined Total Whole Weight(kg): } \\
23000\end{array}$ \\
\hline Emissions & EM2 & Calcula as emissões & $\begin{array}{c}\text { Variable name: em } \\
\text { Time(h):NORM(12,1.2) } \\
\text { Emissions coeficient: } 1.5 \\
\text { Power: } 136 \\
\text { Load(kg): } 20000 \\
\text { Legal Combined Total Whole Weight(kg): } \\
23000\end{array}$ \\
\hline Emissions & EM3 & Calcula as emissões & $\begin{array}{c}\text { Variable name: em } \\
\text { Time(h):NORM(9,0.9) } \\
\text { Emissions coeficient: } 1.5 \\
\text { Power: } 136 \\
\text { Load(kg): } 20000 \\
\text { Legal Combined Total Whole Weight }(\mathrm{kg}) \text { : } \\
23000 \\
\end{array}$ \\
\hline Emissions & EM4 & Calcula as emissões & $\begin{array}{c}\text { Variable name: em } \\
\text { Time(h): NORM(2,0.2) } \\
\text { Emissions coeficient: } 1.5 \\
\text { Power: } 136 \\
\text { Load(kg): } 20000 \\
\text { Legal Combined Total Whole Weight }(\mathrm{kg}): \\
23000\end{array}$ \\
\hline Emissions & EM5 & Calcula as emissões & $\begin{array}{c}\text { Variable name: em } \\
\text { Time(h): NORM(7,0.7) } \\
\text { Emissions coeficient: } 1.5 \\
\text { Power: } 136 \\
\text { Load(kg): } 23000 \\
\text { Legal Combined Total Whole Weight }(\mathrm{kg}) \text { : } \\
23000\end{array}$ \\
\hline Atribuição & $\mathrm{C} 1$ & $\begin{array}{c}\text { Adiciona uma } \\
\text { variável ao modelo. }\end{array}$ & $\begin{array}{c}\text { Tipo: Variável } \\
\text { Nome: custo } \\
\text { Valor: } \operatorname{NORM}(600,60)\end{array}$ \\
\hline Atribuição & $\begin{array}{l}\mathrm{C} 2, \mathrm{C} 5, \mathrm{C} 8 \\
\mathrm{C} 11 \text { e } \mathrm{C} 14\end{array}$ & $\begin{array}{c}\text { Adiciona uma } \\
\text { variável ao modelo. }\end{array}$ & $\begin{array}{l}\text { Tipo: Variável } \\
\text { Nome: entidades } \\
\text { Valor: entidades+1 }\end{array}$ \\
\hline Atribuição & $\begin{array}{l}\mathrm{C} 3, \mathrm{C} 6, \mathrm{C} 9 \\
\mathrm{C} 12, \mathrm{C} 15\end{array}$ & $\begin{array}{c}\text { Adiciona uma } \\
\text { variável ao modelo. }\end{array}$ & $\begin{array}{l}\text { Tipo: Variável } \\
\text { Nome: emissoes_ind } \\
\text { Valor: em/entidades }\end{array}$ \\
\hline Atribuição & $\mathrm{C} 4$ & $\begin{array}{c}\text { Adiciona uma } \\
\text { variável ao modelo. }\end{array}$ & $\begin{array}{c}\text { Tipo: Variável } \\
\text { Nome: custo } \\
\text { Valor: NORM }(900,90)\end{array}$ \\
\hline Atribuição & $\mathrm{C} 7$ & $\begin{array}{c}\text { Adiciona uma } \\
\text { variável ao modelo. }\end{array}$ & $\begin{array}{l}\text { Tipo: Variável } \\
\text { Nome: custo } \\
\text { Valor: NORM }(1100,110)\end{array}$ \\
\hline Atribuição & $\mathrm{C} 10$ & $\begin{array}{c}\text { Adiciona uma } \\
\text { variável ao modelo. }\end{array}$ & $\begin{array}{l}\text { Tipo: Variável } \\
\text { Nome: custo } \\
\text { Valor: NORM }(1500,150)\end{array}$ \\
\hline Atribuição & & Adiciona uma & Tipo: Variável \\
\hline
\end{tabular}




\begin{tabular}{|c|c|c|c|}
\hline & $\mathrm{C} 13$ & variável ao modelo. & $\begin{array}{c}\text { Nome: custo } \\
\text { Valor: } \operatorname{NORM}(300,30) \\
\end{array}$ \\
\hline Atribuição & C16 & $\begin{array}{c}\text { Adiciona uma } \\
\text { variável ao modelo. }\end{array}$ & $\begin{array}{c}\text { Tipo: Variável } \\
\text { Nome: approved } \\
\text { Valor: approved+1 }\end{array}$ \\
\hline Atribuição & $\mathrm{C} 17$ & $\begin{array}{c}\text { Adiciona uma } \\
\text { variável ao modelo. }\end{array}$ & $\begin{array}{c}\text { Tipo: Variável } \\
\text { Nome: disapproved } \\
\text { Valor: disapproved+1 }\end{array}$ \\
\hline Jump & A1 & Executa um "salto" & Origem \\
\hline Jump & A1 & Executa um "salto" & Destino \\
\hline $\mathrm{X}$ (Decisor) & $\mathrm{X} 1$ & $\begin{array}{l}\text { Desvia a execução } \\
\text { de uma função. }\end{array}$ & $\begin{array}{l}\text { Tipo: AG N-way-by-condition } \\
\text { Expression (1) if true: } a g==1 \\
\text { Expression (2) if true: } a g==2 \\
\text { Expression (3) if true: } a g==3 \\
\text { Expression (4) if true: } a g==4 \\
\text { Expression (5) if true: } a g==5\end{array}$ \\
\hline $\begin{array}{c}\text { Configuração } \\
\text { AG }\end{array}$ & Optimize & Configura o AG & $\begin{array}{c}\text { Tools - Optmize: } \\
\text { Variable Name: ag1 } \\
\text { Min.value: } 0 \\
\text { Max.value: } 2 \\
\text { Variable Name: ag2 } \\
\text { Min.value: } 0 \\
\text { Max.value: } 1 \\
\text { Objective: approved } \\
\text { Is minimizing? no } \\
\end{array}$ \\
\hline $\mathrm{X}$ (Decisor) & $\mathrm{X} 2$ & $\begin{array}{l}\text { Desvia a execução } \\
\text { de uma função. }\end{array}$ & $\begin{array}{c}\text { Tipo: RNA com } 2 \text { caminhos } \\
\text { Arquivo de Treinamento: C: } \backslash \text { Mestradol } \\
\text { |Simulação aplicada a logistica e } \\
\text { manufaturaltreinamento1.txt } \\
\text { Algoritmo: ResilientPropagation } \\
\text { Exp. Neurônio 1: emissoes_ind } \\
\text { Exp. Neurônio 2: custo } \\
\text { Exp. Neurônio 3: } 0 \\
\text { Exp. Neurônio 4: } 0 \\
\text { Exp. Neurônio 5: } 0 \\
\mathrm{~N}^{\circ} \text { Neurônios Camada Entrada: } 2 \\
\mathrm{~N}^{\circ} \text { Neurônios Camada Oculta: } 6 \\
\mathrm{~N}^{\circ} \text { Neurônios Camada Saída: } 1\end{array}$ \\
\hline
\end{tabular}

